\title{
Originals
}

\section{Variations in renal threshold for glucose in Type 1 (insulin-dependent) diabetes mellitus}

\author{
K. Johansen, P.Aaby Svendsen and B. Lørup \\ Steno Memorial Hospital, Gentofte, Denmark
}

\begin{abstract}
Summary. The blood glucose/urinary glucose relationship was studied in 23 patients with Type 1 (insulin-dependent) diabetes. Glucose was infused intravenously in order to increase blood glucose concentration slowly and gradually. The renal threshold was recorded at the slightest trace of glycosuria and varied by a factor of 2 (from 6.0 to $14.3 \mathrm{mmol} / \mathrm{l}$ ). The rise in blood glucose required to change the urinary output (0-1.1 mmol glucose $/ 20 \mathrm{~min})$ varied by a factor of 7 $(1.1-7.6 \mathrm{mmol} / \mathrm{l})$. The maximal rate of tubular glucose reabsorption varied by a factor of $2(0.93-1.98 \mathrm{mmol} / \mathrm{min})$. The renal threshold was negatively correlated with the creatinine clearance $(r=-0.52, p<0.05)$, but was not correlated with diabetic control, age or duration of diabetes. The maximal rate of glucose reabsorption was negatively correlated with age
\end{abstract}

$(r=-0.47, p<0.05)$ and duration of diabetes $(r=-0.54, p<$ $0.05)$. In conclusion, urinary glucose excretion is dependent on both renal threshold and the splay and the slope of the blood glucose/urinary glucose excretion curve. Thus, the degree of glycosuria is of value as an index of diabetic control only when the blood glucose/urinary glucose relationship is known. The inverse correlation between renal threshold and creatinine clearance limits the usefulness of measuring glycosuria in patients with nephropathy.

Key words: Renal threshold, splay, creatinine clearance, maximal rate of renal tubule glucose absorption, glycosuria, nephropathy, Type 1 diabetes, diabetic control.
The degree of glycosuria is still the most universally used measure of diabetic control. Glucose is freely filtered at the glomerulus and reabsorbed in the proximal convoluted tubule. The amount of glucose reabsorbed increases linearly with rising plasma glucose concentration until a maximum value $\left(\mathrm{Tm}_{\mathrm{G}}\right)$ is reached. Any further increase in the filtered glucose load is excreted in the urine. The concentration in plasma at which glucose appears in the urine is the renal threshold for glucose $\left(\mathrm{RT}_{\mathrm{G}}\right)$. Therefore, in order to use urinary glucose excretion as an index of diabetic control, the blood glucose/ urinary glucose relationship must be known. Deviations in $\mathrm{RT}_{\mathrm{G}}$ above or below the normal threshold of $10 \mathrm{mmol} / 1$ are commonly found.

More recent studies of the relationship between the degree of glycosuria and the blood glucose level show their poor correlation [1-5]. Among the reasons for this discrepancy are the time lag between the filtration of glucose in the glomeruli and emptying of the bladder, incomplete urine collection, differences in renal threshold and the fact that urine tests give no information about blood glucose levels below the renal threshold.

The aim of the present work was to study the differences in $\mathrm{RT}_{\mathrm{G}}$ and its relationship to creatinine clearance, $\operatorname{Tm}_{\mathrm{G}}$, age, duration of diabetes and metabolic control in patients with Type 1.

\section{Patients and methods}

Thirty-five patients with Type 1 diabetes were studied after informed consent. Twelve of these patients were later excluded, nine because of insufficient bladder emptying (shown by a coefficient of variation of creatinine clearance of $>10 \%$ ) and three due to other technical problems. Thus, 23 patients with Type 1 diabetes (Table 1) were studied in the morning, fasting and with omission of their morning insulin. Seven of the patients had persistent proteinuria and decreased creatinine clearance. Short-acting insulin was infused IV (Infusomat) until the patients were aglycosuric. Infusion of isotonic glucose $(5.5 \%)$ was then started at a rate causing the blood glucose to rise slowly and gradually at $1 \mathrm{mmol} \cdot \mathrm{1}^{-1} \cdot 20 \mathrm{~min}^{-1}$. Urine was collected in 20-min periods and the glucose concentration measured quantitatively. Capillary whole blood glucose was measured every $10 \mathrm{~min}$. In order to ensure a high diuresis, $1000 \mathrm{ml}$ of tap water was taken orally during the hour before the test and $100-200 \mathrm{ml} / 20 \mathrm{~min}$ during the study. Measurements were carried out with the patients in the supine position.

The $\mathrm{RT}_{\mathrm{G}}$ was defined as the blood glucose concentration at the

Table 1. Clinical details of 23 patients with Type 1 diabetes

\begin{tabular}{lllll}
\hline $\begin{array}{l}\mathrm{Sex} \\
\mathrm{M}: \mathrm{F}\end{array}$ & $\begin{array}{l}\text { Age } \\
\text { (years) }\end{array}$ & $\begin{array}{l}\text { Duration } \\
\text { of diabetes } \\
\text { (years) }\end{array}$ & $\begin{array}{l}\text { M-value } \\
\text { (arbitrary } \\
\text { units) } \\
(n=23)\end{array}$ & $\begin{array}{l}\mathrm{HbA}_{1 \mathrm{c}} \\
(\%) \\
(n=13)\end{array}$ \\
\hline $18: 5$ & $32 \pm 14$ & $11 \pm 10$ & $\begin{array}{l}50 \pm 29 \\
(8-127)\end{array}$ & $\begin{array}{c}9.3 \pm 1.4 \\
(7.4-11.6)\end{array}$ \\
\hline
\end{tabular}

Expressed as mean \pm SD with range in parentheses 


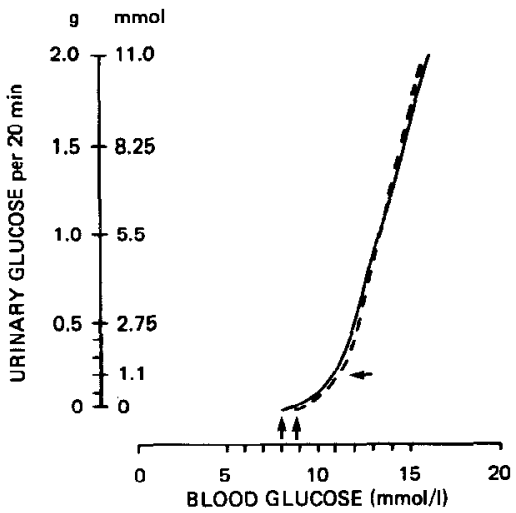

Fig. 1. Blood glucose/urinary glucose titration curves in one patient determined on two occasions 3 months apart. The splay is defined as that part of the curves from the renal threshold $(\uparrow \uparrow)$ to a glucose excretion of $1.1 \mathrm{mmol} / 20 \mathrm{~min}(\longleftarrow)$

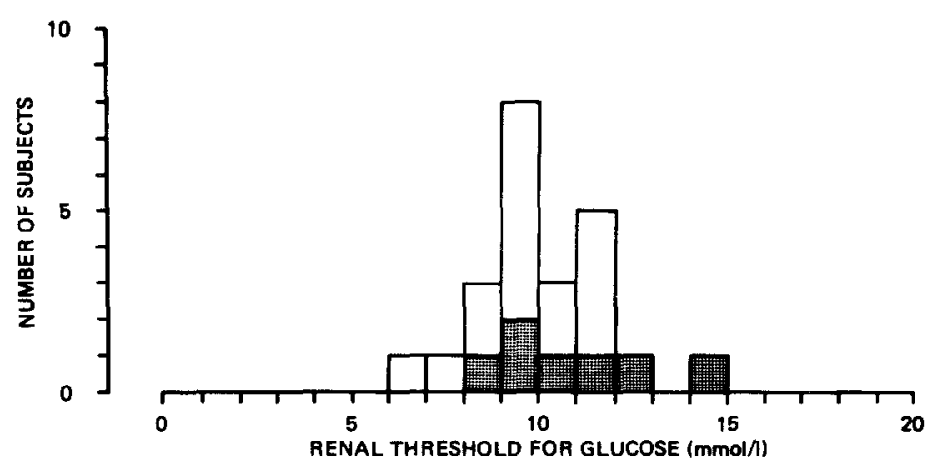

Fig. 2. Distribution of renal threshold in 23 patients with Type 1 diabetes. The hatched bars indicate patients with persistent proteinuria and decreased creatinine clearance

start of the 20-min period where the first trace of glycosuria was found $(0.56 \mathrm{mmol} / 1)$. The 'splay' (the curved part of the blood glucose/urinary glucose titration curve, i. e. that part of the curve between the renal threshold and the linear part) was arbitrarily defined as the rise in blood glucose level required to increase urinary glucose excretion from 0 to $1.1 \mathrm{mmol} / 20 \mathrm{~min}$ (Fig. 1) [6].

For comparison, $\mathrm{RT}_{\mathrm{G}}$ was also calculated from correlations between the mean blood glucose concentrations (five blood glucose values/day at $08.00,11.00,14.00,17.00,22.00 \mathrm{~h}$ ) and the 24 -h glucose excretion during three admission days before the infusion study. In three patients, this method was unapplicable due to a high $\mathbf{R T}_{\mathrm{G}}$ and no glycosuria.

Creatinine clearance was measured during the last three to four 20-min periods. $\operatorname{Tm}_{\mathrm{G}}$ was calculated from the straight part of the urinary glucose/blood glucose titration curve using the formula: $\operatorname{Tm}_{G}=$ creatinine clearance $\times$ plasma glucose (blood glucose $\times 1.15$ ) minus urinary excretion rate (urine flow $x$ urinary glucose concentration).

Blood and urinary glucose levels were measured with a glucose oxidase method [7]. The sensitivity of the test for urinary glucose was $0.55 \mathrm{mmol} / \mathrm{l}$. Glycosylated haemoglobin (stable $\mathrm{HbA}_{\mathrm{lc}}$ ) was determined as described previously [8]. The M-value was calculated according to Schlichtkrull et al. [9].

Conventional parametric correlation coefficients were calculated.

\section{Results}

The correlation between mean blood glucose and urinary glucose excretion 3 days before the $\mathrm{RT}_{\mathrm{G}}$ study was low $(r=0.51, p<0.05)$.

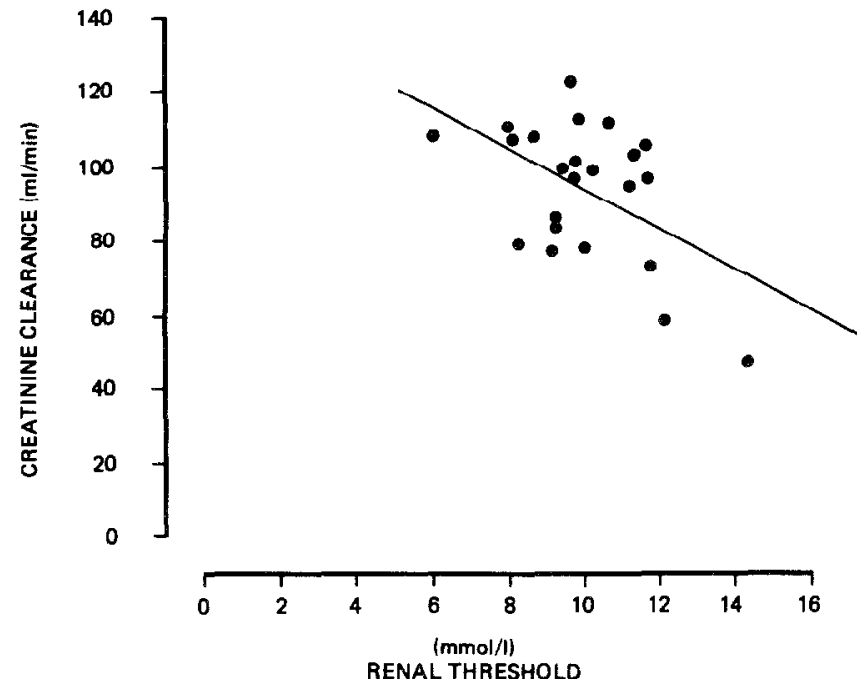

Fig. 3. Correlation between threshold and creatinine clearance. $r=-0.52, p<0.05, \mathrm{y}=-5.5 \mathrm{x}+148.9, n=23$

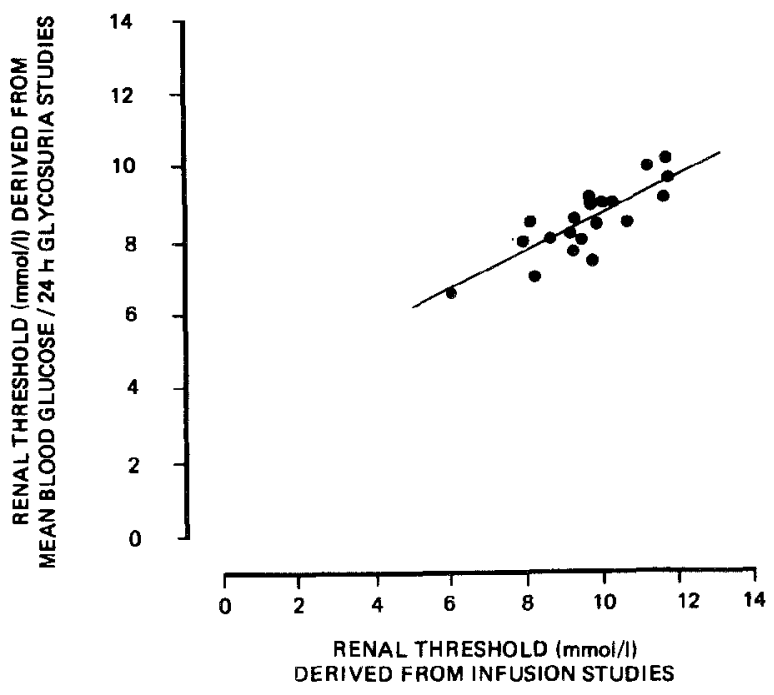

Fig.4. Correlation between renal threshold estimated from mean blood glucose $/ 24 \mathrm{~h}$ glycosuria and from infusion studies. $r=0.84$, $p<0.001, \mathrm{y}=0.56 \mathrm{x}+3.14, n=20$

During the $\mathrm{RT}_{\mathrm{G}}$ study, the urinary flow during the first period with glycosuria varied from 88 to $479 \mathrm{ml} /$ $20 \mathrm{~min}(281 \pm 109 \mathrm{ml} / 20 \mathrm{~min}$, mean $\pm \mathrm{SD})$ and the amount of glucose excretion varied from 0.46 to $7.74 \mathrm{mmol}$ (mean $1.70 \pm 1.81 \mathrm{mmol} / 1)$. The rise in blood glucose during the 20 -min period preceding the first period with glycosuria varied from 0.2 to $1.9 \mathrm{mmol} / \mathrm{l}$ (mean $1.1 \pm 0.5 \mathrm{mmol} / 1$ ).

Mean creatinine clearance was $100 \pm 22 \mathrm{ml} / \mathrm{min}$ (range $47-140 \mathrm{ml} / \mathrm{min}$ ), the mean renal threshold was $10.0 \mathrm{mmol} / 1(6.0-14.3 \mathrm{mmol} / 1)(\mathrm{Fig} .2)$, the mean splay $2.7 \mathrm{mmol} / \mathrm{l}(1.1-7.6 \mathrm{mmol} / \mathrm{l})$ and the mean $\operatorname{Tm}_{\mathrm{G}}$ $1.37 \mathrm{mmol} / \mathrm{min}(0.93-1.98 \mathrm{mmol} / \mathrm{min})$.

$\mathrm{RT}_{\mathrm{G}}$ as well as the splay were correlated with creatinine clearance, although these correlations were weak $(r=-0.52, p<0.05$ and $-0.53, p<0.05$, respectively (Fig. 3). There was no correlation between renal threshold and age, duration of diabetes, $\mathrm{HbA}_{\mathrm{lc}}$, M-value, uri- 
nary flow or splay. The coefficient of variation of $\mathrm{RT}_{\mathrm{G}}$ in six patients studied twice with a 3-month interval was $12 \%$.

The $\operatorname{Tm}_{\mathrm{G}}$ was negatively correlated with age $(r=-0.47, p<0.05)$ and with duration of diabetes $(r=-0.54, p<0.05)$. $\mathrm{Tm}_{\mathrm{G}}$ was not correlated with $\mathrm{RT}_{\mathrm{G}}$, urinary flow, splay, or M-value.

Figure 4 shows the correlation between the two methods of estimating the renal threshold $(r=0.84$, $p<0.001$ ). There was good agreement in the low range, but $\mathrm{RT}_{\mathrm{G}}$ values based on infusion experiments were higher than those based on correlations between mean blood glucose and 24-h glycosuria in the medium and high ranges.

\section{Discussion}

The present study demonstrates that the $\mathrm{RT}_{\mathrm{G}}$ and the splay vary greatly and are negatively correlated with creatinine clearance in Type 1 diabetes. It has previously been shown that diabetic glomerulosclerosis in longterm diabetes is associated with a raised renal threshold for glucose $[10,11]$. This means that the assessment of control of patients with Type 1 diabetes based on urinary glucose excretion is difficult, particularly in those with nephropathy, unless the blood glucose/urinary glucose excretion relationship is known. The sensitivity of the method for urinary glucose obviously influences the results. The sensitivity of the method used in the present work was $0.55 \mathrm{mmol} / 1$, which is in the order of magnitude of many commercial strip methods used by patients. In the present study, variation in urinary glucose excretion only explained $26 \%$ of the variation in mean blood glucose during 3 days before the $\mathrm{RT}_{\mathrm{G}}$ study. However, it is not feasible to perform blood glucose/urinary glucose titration curves in all patients with Type 1 diabetes. In a recent paper, Walford et al. [12] found the renal threshold of diabetic patients to vary from 3 to $10 \mathrm{mmol} / 1$ (mean $7.2 \mathrm{mmol} / 1$ ). The study was based on home measurements of blood glucose (StatTek system) and urinary glucose (Diastix). $\mathrm{RT}_{\mathrm{G}}$ was defined as the mean of the blood glucose concentration $1 \mathrm{~h}$ before and at the time when the urine changed from $0 \%$ to $0.1 \%$ or $0.25 \%$ glycosuria (5.5 or $13.8 \mathrm{mmol} / 1$ ). This degree of glycosuria is much higher than the degree of glycosuria in the first period of urine collection in the present study. This would tend to give a higher $\mathrm{RT}_{\mathrm{G}}$ than the study of Walford et al., but the opposite was the case. The rise in blood glucose in the study of Walford et al. may have been from a concentration far below $\mathrm{RT}_{\mathrm{G}}$ and, thereby, the use of too low a blood glucose level for defining $\mathrm{RT}_{\mathrm{G}}$ may explain the lower $\mathrm{RT}_{\mathrm{G}}$ values in their study.

In our study, $\mathrm{RT}_{\mathrm{G}}$ was not related to age, duration of diabetes, metabolic control, or splay. $\mathrm{RT}_{\mathrm{G}}$ measured on two occasions with a 3- to 4-month interval showed no significant change. Walford et al. found that $\mathrm{RT}_{\mathrm{G}}$ was weakly correlated with age $(r=0.30, p<0.02)$ and with mean blood glucose $(r=0.50, p<0.01)$ when they excluded patients with proteinuria.

The inverse correlation between $\mathrm{Tm}_{\mathrm{G}}$ and age and duration of diabetes may be explained by the falling creatinine clearance with age and duration of diabetes. $\mathrm{Tm}_{\mathrm{G}}$ was not correlated with $\mathrm{RT}_{\mathrm{G}}$, splay or metabolic control.

We found no correlation between urinary flow and $\mathrm{RT}_{\mathrm{G}}$ and $\mathrm{Tm}_{\mathrm{G}}$, suggesting that water loading does not influence $\mathrm{RT}_{\mathrm{G}}$.

It is not practical to perform infusion studies in all diabetic patients in order to determine $\mathrm{RT}_{\mathrm{G}}$. A rough estimate of $\mathrm{RT}_{\mathrm{G}}$ can be obtained by correlating the mean blood glucose levels and the 24-h urinary glucose excretion. The method is, however, not feasible in patients with a high threshold and no glycosuria and, in the higher range, it gives lower values than $\mathrm{RT}_{\mathrm{G}}$ estimated from infusion studies.

Having documented the limitations testing for glycosuria, in assessing metabolic control, we think they should be used only when blood glucose monitoring is impossible for practical or economic reasons. In 'superregulated' patients with no glycosuria this is obviously a conditio sine qua non.

\section{References}

1. Morris LR, McGee JA, Kitabchi AE (1981) Correlation between plasma and urine glucose in diabetes. Ann Int Med 94: 469-71

2. Tattersall R, Gale E (1981) Patient self-monitoring of blood glucose and refinements of conventional insulin treatment. Am J Med 70: 177-182

3. Guthrie DW, Hinnen D, Guthrie RA (1979) Single-voided versus double-voided urine testing. Diabetes Care 2: 269-271

4. Peacock I, Tattersall R (1982) Methods of self-monitoring of diabetic control. Clin Endocrinol Metabol 11: 485-501

5. Malone JI, Hellrung JM, Malphus EW, Rosenbloom AL, Grgic A, Weber FT (1976) Good diabetes control - a study in mass delusion. J Pediatr 88: 943-947

6. DeFronzo RA, Thier SO (1981) Renal glucose handling - normal physiology. In: Brenner BM, Rector FC Jr (eds) The kidney. WB Saunders, Philadelphia, London, Toronto, pp 1839-1841

7. Trinder $P$ (1969) Determination of glucose in blood using glucose oxidase and an alternative oxygen receptor. Ann Clin Biochem 6: 24-27

8. Svendsen P Aa, Christiansen JS, Søegaard U, Welinder BS, Nerup J (1980) Rapid changes in chromotographically determined haemoglobin $\mathrm{A}_{1 \mathrm{c}}$ induced by short-term changes in glucose concentration. Diabetologia 19:130-136

9. Schlichtkrull J, Munck O, Jersild M (1965) The M-value, an index of blood-sugar control in diabetics. Acta Med Scand 177: 95-102

10. Lundbæk K (1953) Long-term diabetes. Ejnar Munksgaard, Copenhagen

11. Robertsen JA, Gray CH (1953) Mechanism of lowered renal threshold for glucose in diabetes. Lancet $2: 12-15$

12. Walford S, Page MMcB, Allison SP (1980) The influence of renal threshold on the interpretation of urine tests for glucose in diabetic patients. Diabetes Care 3: 672-674

Received: 22 March 1983

and in revised form: 21 November 1983

Dr. K. Johansen

Steno Memorial Hospital

Niels Steensens Vej 2

2820 Gentofte, Denmark 